\title{
Nossas virtudes: sobre o capítulo 7 de Para além de bem e mal*
}

\author{
Paul van Tongeren ${ }^{* *}$
}

\begin{abstract}
Resumo: Qual é a mensagem do sétimo capítulo de Para Além de Bem e Mal, intitulado 'Nossas Virtudes'? Inicialmente apresento uma análise da estrutura do capítulo (que parece ser o capítulo central da segunda metade do livro). Constata-se por meio desta análise que as seções 214 e 227 ocupam um lugar especial no capítulo. Uma análise detida destas duas seções sugere que neste capítulo o leitor é introduzido em uma condição tipicamente nietzschiana: o questionamento crítico da moralidade torna-se autorreferencial: aquele que questiona torna questionável o seu próprio questionamento. $\mathrm{O}$ mesmo procedimento adotado na seção 1 do primeiro capítulo em relação à filosofia e à vontade de verdade (tanto a vontade de verdade tradicional quanto a "nossa" própria) é adotado agora na segunda metade do livro em relação à "honestidade" ou "probidade" [Redlichkeit] e aplicado à moralidade (tanto a tradicional quanto a "nossa" virtude moral). O que no início parecia ser uma apresentação da virtude moral do espírito livre se revela agora como uma "autossupressão" da moralidade. Esta interpretação recebe uma elaboração e confirmação adicionais pela luz que ela permite lançar sobre as seções supostamente antifeministas que encerram o capítulo.
\end{abstract}

Palavras-chave: virtude - moralidade - honestidade - probidade

* Tradução de Wander Andrade de Paula. Revisão técnica de Rogério Lopes.

** Professor da Radboud University Nijmegen, Holanda.

Correio eletrônico: p.vantongeren@ftr.ru.nl 
van Tongeren, P.

\section{Introdução}

Nietzsche não escreveu livros do tipo que nós comumente lemos ou escrevemos: ele não partia de um esboço, para depois ir elaborando e desenvolvendo gradativamente em uma explanação sistemática. Ao menos em seu período mais produtivo, seus livros eram aforismáticos e tratavam dos mais variados temas, em uma ordenação que nem sempre é fácil de interpretar. Nietzsche nunca escreveu, por exemplo, um capítulo de livro sobre as "nossas virtudes". Ao invés disso, reuniu em determinado momento uma certa quantidade de aforismos que havia escrito em épocas e lugares muito diferentes, $\mathrm{e}$ que ele reelaborou mais uma vez em lugares e épocas diferentes, $\mathrm{e}$ finalmente organizou em uma ordem própria; ele atribuiu a tal coleção o título "Nossas virtudes" e a estabeleceu como o capítulo VII de um livro intitulado Para além de bem e mal. Se nós tentarmos entender o que ele queria dizer, temos como material a ser interpretado não apenas textos, mas também o modo com que eles foram reunidos e ordenados. Permitam-me, por essa razão, começar com algumas sugestões sobre a estrutura do livro e do capítulo.

\section{A estrutura do capítulo VII}

Não parece ser nenhum atrevimento excessivo dividir Para além de bem e mal em aproximadamente duas metades, a primeira (capítulos 1 a 4) centrada principalmente (embora não exclusivamente) na filosofia, a segunda (capítulos 5 a 9) principalmente na moralidade. Como sabemos, o livro foi desenvolvido a partir de um plano de reelaboração de Humano, demasiado humano I, origem que pode ainda ser reconhecida no fato de que ambos os livros contêm 9 capítulos, com tópicos aproximadamente similares em ambos. Já no decurso de seu trabalho no primeiro capítulo de Humano, Nietzsche mudou sua opinião e começou a trabalhar em um novo livro: Para além 
de bem e mal. O tema do segundo capítulo de Humano ("Contribuição à história dos sentimentos morais") foi deslocado para o início da segunda metade do novo livro (Capítulo V: "Contribuição à história natural da moral"), possivelmente no intuito de distinguir mais claramente os dois temas principais de sua obra: por um lado, filosofia, conhecimento, a vontade de verdade; e, por outro, a moralidade.

Nosso capítulo 7 poderia ser então identificado como o capítulo central da segunda metade do livro, dedicado a esse segundo tema. Aqui - assim poderíamos porventura dizer - a transição é feita a partir de uma descrição e crítica da moralidade do bem e do mal, para algum tipo de moralidade "para além de bem e mal". Mas, como ocorre frequentemente em Nietzsche, essa transição não constitui um simples passo adiante.

O título do capítulo (“Nossas virtudes") é provavelmente um indício importante daquilo que Nietzsche deseja realizar nesse texto. Ele não é certamente uma mera etiqueta para uma pasta na qual o autor reúne todos os textos sobre virtudes. Há dúzias de seções sobre virtudes fora deste capítulo; também sobre "nossas virtudes", i.e., sobre aquelas virtudes que Nietzsche atribui explicitamente tanto a si mesmo, quanto a outros possíveis espíritos livres (JGB/BM 284, KSA 5.231). E, além disso: o termo "virtude" ocorre aproximadamente em apenas um terço dos aforismos que ele agrupou neste capítulo, e ainda assim "virtudes", em geral, ou "nossas virtudes", em particular, não são temas centrais desses textos.

Entretanto, creio que o título do capítulo seja importante. Tratase de um título de fato provocativo: "nossas virtudes". À primeira vista, pode parecer que o grande crítico da moralidade começa agora a falar de sua própria moralidade, ou ao menos sobre suas próprias virtudes. O leitor pode se sentir aliviado ("ah - finalmente fica claro que há, apesar de tudo, alguma moralidade disponível...”), mas isso não irá durar por muito tempo. O título da primeira seção do capítulo repete a fórmula "nossas virtudes", mas lhe acrescenta um ponto de 
van Tongeren, $\mathrm{P}$.

interrogação: "nossas virtudes?" i.e.: ainda temos realmente virtudes? $\mathrm{E}$, se assim for, como elas se relacionam com aquelas de nossos "avós"? São similares? Devem ser distinguidas das antigas? Podem ser distinguidas? Somos lembrados das questões suspeitas com as quais Nietzsche abre o quinto livro d'A gaia ciência: não devemos reconhecer que mesmo nós, espíritos livres, somos ainda inspirados por essa mesma moralidade que criticamos? A busca por "nossas virtudes" deve se desenvolver em direção à descoberta de que nós também estamos aprisionados no niilismo que havíamos revelado. A transição não é, de fato, um simples passo adiante; mesmo este "ultrapassamento" [going over] deve ser um 'declínio' [going under] (FW/GC 342, KSA 3.571); a transição deve se mostrar como um passo em direção à tragédia.

A importância do título é confirmada por outra característica estrutural do texto do capítulo. A fórmula é não apenas repetida no título da primeira seção, ela ocorre novamente no texto da seção que se situa no meio exato do capítulo. $\mathrm{O}$ capítulo contém, se contabilizamos cuidadosamente, 27 seções. De forma bastante curiosa, Nietzsche reúne as "sete máximas de mulher" sob um número (237), mas então repete o mesmo número 237 para a seção subsequente. Se contabilizarmos duas seções 237, há 27 seções nesse capítulo, das quais a 227 ocupa a posição central entre dois grupos de 13 seções cada. Penso que Nietzsche usou com bastante frequência seções de abertura e encerramento, bem como seções centrais, com o intuito de demarcar uma linha que ele gostaria de seguir no capítulo. E esse parece ser certamente o caso aqui. A seção 227 se inicia com a suposição de que a "probidade" [Redlichkeit] possa ser "nossa virtude".

O título do capítulo provavelmente indica algo que será buscado no seu decorrer. Na primeira seção a busca é introduzida como tal, e na seção central uma hipótese é formulada, possivelmente à base daquilo que foi feito na primeira metade do capítulo. Encontraremos, 
ao final do mesmo, i.e., nos textos supostamente antifeministas com os quais o capítulo se encerra, aquilo que foi buscado? Tentemos averiguar e olhar mais cuidadosamente o que ocorre nesse intervalo.

Mas primeiro devemos notar que há uma considerável ambivalência em ambos os textos-chave que identificamos até agora. Na seção de abertura (214) a busca por nossas virtudes é anunciada, mas ao mesmo tempo questionada: "nós" esperamos que "nossas virtudes" sejam diferentes daquelas de nossos avós; mas "buscar suas próprias virtudes [...] seria quase: crer em sua própria virtude? Mas esse 'crer em sua virtude' - não é afinal o mesmo que outrora se chamava 'boa consciência', aquela venerável, longa trança conceitual que nossos avós prendiam atrás da cabeça, e muitas vezes também no entendimento?" (JGB/BM 214, KSA 5.151)1. Então, quão diferente são as nossas virtudes, no final das contas? Uma dúvida similar é levantada por uma similar ambivalência que encontramos na seção central (JGB/BM 227, KSA 5.162). Aqui Nietzsche lança a hipótese de que a "probidade" possa ser a "nossa virtude". Mas ao fim dessa seção ele alerta o leitor, bem como a si mesmo, de que essa probidade não deve se tornar a nossa "estupidez", i.e.: nossa virtude, uma vez que "toda virtude tende à estupidez, toda estupidez à virtude."

Podemos concluir até aqui que o sétimo capítulo nos introduz em uma condição tipicamente nietzschiana: o questionamento crítico da moralidade vem sendo realizado de modo autorreferencial: o questionador torna questionável [fragwürdig] o seu próprio questionar. Reconhecemos a estratégia do início do livro: na seção 1 de Para além de bem e mal Nietzsche mostra como não apenas a filosofia tradicional, mas também o nosso próprio questionar, é motivado por uma vontade de verdade que em si mesma está sendo colocada agora em questão. O resultado é "um encontro, ao que parece, entre interrogações e pontos de interrogação" (JGB/BM 1, KSA 5.15). O que Nietzsche fez naquela ocasião em relação à filosofia e à vontade

1 Todas as citações dos trechos das obras Nietzsche foram traduzidas por Paulo César de Souza. 
van Tongeren, $\mathrm{P}$.

de verdade (tanto a tradicional quanto a "nossa" própria) é, agora, na segunda metade do livro, repetido sob o nome de "probidade" e aplicado à moralidade (mais uma vez: a tradicional, e também a "nossa" virtude).

\section{Para além de bem e mal: quem somos "nós"?}

Usei até aqui o "nós" nietzschiano como se fosse claro a quem ou ao quê esse pronome pessoal se refere. Analisemos mais de perto como ele é introduzido na seção de abertura (JGB/BM 214, KSA 5.151).

"Nós" somos, de acordo com essa seção, "europeus de amanhã", i.e., não os atuais europeus que são envenenados pelo cristianismo (JGB/BM 62, KSA 5.81), enfraquecidos pela moralidade do rebanho (JGB/BM 199 e 201, KSA 5.119, 121) e barbarizados pela democracia (JGB/BM 224, KSA 5.157). "Nós" somos diferentes das pessoas atuais, mas, de acordo com a penúltima sentença da seção 214, apesar disso, os "últimos europeus com boa consciência". Os europeus de depois amanhã são ainda mais ou menos do dia de hoje. A sua "multiplicidade e arte do travestimento" não torna fácil identificá-los.

É provável que uma transição aconteça nesses indivíduos. Nietzsche os denomina ainda de "primogênitos do século XX". O termo alemão "Erstling" se refere claramente à oblação: como a primeira colheita, esses primogênitos serão sacrificados. Esse sacrifício (ou melhor: esse ser sacrificado) é também apresentado como um resultado do risco que esses indivíduos assumem. Eles têm uma "perigosa curiosidade": perigosa porque aqueles que a possuem estão buscando algo que não se deve tentar capturar. Somos mais uma vez lembrados da seção 1, em que Édipo é mencionado: ele buscou sua própria origem; e nesse texto o filósofo buscou a origem ou a fonte de seu instinto mais básico: a vontade de verdade. Aqui na seção 214 o "nós” está buscando outra fonte: as virtudes a partir 
das quais a nossa vida se origina. Nós arriscamos o destino de Édipo por causa dessa busca?

Buscamos virtudes que assumimos que temos. Embora leiamos na primeira linha da seção 214 que "é provável que também nós tenhamos ainda nossas virtudes", essa alegação é imediatamente enfraquecida na segunda sentença, onde lemos "se tivermos virtudes". Essa reserva gera e ao mesmo tempo torna a busca mais intrincada.

Se ainda tivéssemos virtudes, elas aprenderiam "a se harmonizar com os nossos mais íntimos e autênticos pendores, com as nossas mais ardentes necessidades" (JGB/BM 214, KSA 5.151). Por essa razão, elas serão diferentes daquelas "ingênuas, inteiriças virtudes" de "nossos avós". Elas serão muito mais sofisticadas, curiosas, prudentes, desconfiadas. Por exemplo: se a "probidade" fosse uma de nossas virtudes (ou nossa única virtude, como a seção 227 sugere), ela seria uma probidade cruel, como Nietzsche a apresenta nas seções 229 e 230, i.e., na introdução aos seus textos antifeministas. Essa "crueldade" será diferente da "branda e como que adocicada crueldade de espírito e de sentidos" que nos caracteriza agora. A diferença pode ser que nossa "suave" e "adocicada" crueldade ainda mascara a si mesma agora como uma virtude, a virtude da probidade; ela pode não precisar mais de tal esconderijo no final. Mas em que medida essa "perigosa curiosidade" e "crueldade" do futuro estão relacionadas à virtuosidade do presente (e à virtuosidade antiquada)? E o que significa dizer que ela ainda está vinculada com aquilo que desmascara e põe em questão?

Ao fim da seção, o "nós" é dividido em dois: por um lado, "vocês" e, por outro, o "eu" autoral: "Ah, se vocês soubessem com que rapidez, com que rapidez - isso mudará!..." Isso mal pode ser ainda uma surpresa: a "perigosa curiosidade" do início do texto refere-se à "curiosidade aguda e requintada" ou ao "ânimo de aventura" da seção 227; e isso nos lembra da seção de encerramento do capítulo 1, na qual Nietzsche anuncia a sua aventura de exploração da moralidade. 
van Tongeren, $\mathrm{P}$.

Lá nós lemos: “muito bem: Cerrem os dentes! Olhos abertos! Mão firme no leme! - navegamos diretamente sobre a moral e além dela, sufocamos, esmagamos talvez nosso próprio resto de moralidade, ao ousar fazer a viagem até lá" (JGB/BM 23, KSA 5.38). Quando na seção 214 ele iniciou essa viagem, e está procurando suas virtudes, recorda tal risco e alerta mais uma vez: "muito bem, busquemo-las então em nossos labirintos! - onde, como se sabe, tanta coisa se extravia, tanta coisa é perdida para sempre" (JGB/BM 214, KSA 5.151).

Essa ambiguidade do "nós" sugere um desenvolvimento dramático: o espírito livre irá descobrir que a moralidade criticada sobrevive em sua investigação crítica e em seu criticismo da moralidade; ele terá então que aplicar o seu criticismo a ela mesma e a si mesmo. E, ao fazer o seu criticismo autorreferencial, algo será "perdido para sempre". A virtude irá se perder a si mesma, o virtuoso irá perder a sua virtude. Para muitos isso será também perigoso; eles irão desistir de embarcar nessa viagem: o "nós" se transforma em "vocês". O primogênito terá de ser sacrificado. E isso ocorrerá em breve, de acordo com a linha final: "com que rapidez, com que rapidez - isso mudará!..." (JGB/BM 214, KSA 5.151) Veremos que isso ocorrerá apenas 13 seções adiante, na de número 227. Até chegarmos lá, encontramos um tipo de sumário da crítica de Nietzsche e do seu criticismo da moralidade como já conhecemos de livros anteriores. A autorreferencialidade desse criticismo torna-se visível agora e em seguida (JGB/BM 218 e 221, KSA 5.153, 155), mas será destacada apenas na seção 227 , à qual passamos agora.

\section{Para além de bem e mal 227: probidade?}

Mas primeiro lancemos um rápido olhar às seções imediatamente precedentes, no intuito de preparar a nossa leitura dessa segunda e mais radical discussão da busca por "nossas virtudes" (Cf. JGB/BM 
Nossas virtudes: sobre o capítulo 7 de Para além de bem e mal

227, KSA 5.162). A expressão “nossas virtudes" aparece novamente na seção 224, aqui para indicar as nossas virtudes como "homens do "sentido histórico", que são: "despretensiosos, desinteressados, modestos, bravos, plenos de autossuperação, de dedicação, muito gratos, muito pacientes e acolhedores" (JGB/BM 224, KSA 5.157). Por um lado, esses termos possuem certamente - ao menos parcialmente - conotações positivas, também para Nietzsche; mas, por outro lado, eles são completamente rejeitados como "não [sendo] paradigmas do bom gosto". Somos lembrados da ambiguidade da seção de abertura.

Na seção 225 Nietzsche opõe "a nossa compaixão [...] nossa compaixão contrária" à compaixão pregada pela moralidade ("seja hedonismo, seja pessimismo, utilitarismo ou eudaimonismo"): "compaixão contra compaixão". Pode parecer, portanto, que Nietzsche opõe a sua (ou a "nossa") virtude a uma virtude criticada. Mas, para além do fato de que não é imediatamente claro o que esse elogio do "grande sofrimento" tem a ver com a compaixão, ao final do texto, essa completa linha de interpretação, que procura identificar a "nossa compaixão", se torna duvidosa: "há problemas mais elevados do que dor, prazer e compaixão; e toda filosofia que trate apenas disso é ingenuidade. -" (JGB/BM 225, KSA 5.160).

Finalmente, a seção 226 apresenta a ambiguidade de nossa busca por nossa moralidade, i.e., a moralidade de "[nós] imoralistas", em um campo diferente e de uma perspectiva também diferente: agora é antes o campo da deontologia que o campo da teleologia (e, por isso, Nietzsche fala aqui de "nossos deveres", em vez de "nossas virtudes"), e isso mostra a referida ambiguidade a partir de um perspectiva diferente: a saber, não da "nossa", mas da perspectiva dos outros: "estamos envoltos numa severa malha de deveres, e dela não podemos sair - nisso precisamente somos, também nós, 'homens do dever'! [...] Mas não importa o que façamos, os imbecis e as aparências falam contra nós, dizendo: 'Estes são homens sem dever' - sempre temos os imbecis e as aparências contra nós!" (JGB/ 
van Tongeren, $\mathrm{P}$.

$B M$ 226, KSA 5.162)

A maioria dos intérpretes tem lido a seção 227 como a resposta de Nietzsche à questão de quais são as nossas virtudes, ou melhor, no singular: qual é a nossa virtude (ou a nossa virtude mais básica). $\mathrm{O}$ seu nome é "probidade" [Redlichkeit]. Embora acreditemos que haja indiscutivelmente certo comprometimento com tal virtude naquilo que Nietzsche escreve aqui e alhures, há mais do que suficientes razões para olhar mais cuidadosamente para o texto e descobrir o significado dessa virtude; ou, com as palavras de $A$ gaia ciência: "was es mit [dieser Redlichkeit] auf sich hat", "o sentido desta probidade" (FW/GC 343, 3.573).

Quando nós comparamos o texto da seção 227 com uma versão anterior, que se encontra nas anotações não publicadas (KSA 14.365), torna-se claro que Nietzsche mudou a anotação original, adicionando uma ressalva: "supondo que esta seja a nossa virtude" (itálicos meus). Em lugar algum (nem nesta seção ou em qualquer outra) de Para além de bem e mal ele afirma que a probidade seja a "nossa" virtude, a virtude dos espíritos livres. Por meio de uma referência à "probidade" (JGB/BM 227, KSA 5.162), Nietzsche não nos fornece sua resposta à busca/pergunta pelas "nossas virtudes", mas ele antes comenta uma resposta que foi dada a tal questão, seja por outros, seja por ele mesmo em livros anteriores. Há, por exemplo, algumas seções de Aurora que poderíamos referir a esse respeito (M/A 370, 456, 556, KSA 3.244, 275, 325). Mas essa não é definitivamente a resposta que Nietzsche, de forma irrestrita, daria a si mesmo nesse momento. Pelo contrário: nesse momento ele toma distância dessa resposta que aparentemente foi dada. Na seção 230 ele ainda a vincula explicitamente a outras, embora anônimas: "de fato, soaria mais agradável se de nós murmurassem, se nos imputassem e também reputassem, em vez de crueldade, uma certa 'extravagante honestidade', a nós, espíritos livres, muito livres - e quem sabe esta não será, um dia, a nossa - reputação?" (JGB/BM 230, KSA 5.167). 
Por meio dessa formulação, ele cria uma oportunidade para o seu comentário a essa questão, e, como veremos, ainda para a busca/ pergunta em si mesma.

A fórmula "supondo que" ocorre com muita frequência e em momentos bastante decisivos de Pará além de bem e mal2. Essa pode ser ainda identificada como sendo uma característica estrutural do livro como um todo. E em muitos desses casos acreditamos que tal fórmula foi adicionada por Nietzsche apenas na fase final de elaboração da obra. Temos a impressão de que ele queria sublinhar esse aspecto, ou de que ele considerou necessário tornar explícito na versão impressa e publicada de seus pensamentos aquilo que era óbvio para ele. Nietzsche sempre foi perspicaz em prevenir a ossificação de seus pensamentos, tal como poderia resultar de sua publicação (cf. JGB/BM 296, KSA 5.239). Por meio da adição da fórmula "supondo que", ele sublinhou a natureza perspectivística, hipotética e provisória de seu pensamento.

1. Perspectivística: ou ao tomar perspectivas inesperadas ("supondo que a verdade seja uma mulher", JGB/BM Prefácio, KSA 5.11), ou ao tornar o óbvio em uma perspectiva ("suponha que queiramos a verdade", $J G B / B M 1$, KSA 5.15), ele mostra como a perspectiva determina o que nós vemos. A probidade pode parecer "nossa virtude", a partir de uma certa perspectiva. Mas é a tarefa do espírito livre, de acordo com Nietzsche, "aprender a perceber o que há de perspectivista em cada valoração". Ele deve "tornar-se senhor de si mesmo, senhor também de suas próprias virtudes" (MAI/ HHI Prefácio 6, KSA 2.20). A probidade é o que nós vemos de uma (dentre muitas) perspectiva(s), mas devemos cuidar "para que não se torne [...] nosso limite, nossa estupidez!” (JGB/BM 227, KSA 5.162) 2. Hipotética: a natureza hipotética do pensamento de Nietzsche

2 Cf. JGB/BM 3, 22, 25, 29, 36, 201, 210, 227, 231, 255, 269 e 283, KSA 5. 17, 37, 42, 47, 54, 121, 142, 162, 170, 222, 231; cf. também JGB/BM 1, 15, 23, 39, 62, 228, 264, KSA 5.15, 38, $56,81,163,218$, e, de forma mais indireta em $J G B / B M$ 199, 204 e 265, KSA 5.119, 129, 219. 
van Tongeren, $\mathrm{P}$.

faz dele genuinamente experimental e aventureiro. Por meio de suas hipóteses ele concede a si mesmo "o perigoso privilégio de poder viver por experiência e oferecer-se à aventura: o privilégio de mestre do espírito livre!" (MA I/HH I Prefácio 4,KSA 2.17). Ele está embarcando para um destino desconhecido. Também no que diz respeito às "nossas virtudes", muito é ainda desconhecido. A hipótese de que a probidade é a nossa virtude é apenas o ponto inicial da jornada, ela não determina para sempre a sua orientação, quanto menos designaria sua meta final: "e o que sabemos de nós afinal? Como quer chamar-se o espírito que nos guia? [...] Quantos espíritos abrigamos?"

3. Como provisório, por fim, o pensamento de Nietzsche é um prelúdio, uma preparação para algo que pode ser completamente diferente. No que diz respeito à probidade, ele expressa um desejo: "que o seu brilho possa um dia pairar, como uma dourada, azul, sarcástica luz de entardecer, sobre essa cultura minguante e sua seriedade opaca e sombria!" (JGB/BM 227, KSA 5.162). Ele compara a virtude da probidade com o ocaso de uma cultura minguante; e, desse modo, ele aponta para um novo alvorecer, no qual um novo sol, ou ao menos uma nova luz, irá brilhar, e definitivamente não uma "luz de entardecer". Quem sabe a probidade será ainda significativa para as pessoas do novo dia, para estes "europeus de depois de amanhã" (JGB/BM 214, KSA 5.151)? A probidade é o ponto de partida para questões como esta, não a resposta para estas questões. "Nós", que fazemos tais questões, não devemos "nos prender às próprias virtudes" (JGB/BM 41, KSA 5.58).

\section{A última virtude}

Zaratustra denomina a probidade "a mais jovem dentre as virtudes" ( $Z a / Z A$ I Dos Trasmundanos, KSA 4.35). Na seção 456 de Aurora, Nietzsche explica que ela é, na verdade, "a mais jovem 
virtude", porque a "probidade não aparece nem entre as virtudes socráticas, nem entre as cristãs". Seria, contudo, um conclusão precipitada identificá-la, em função disso, como a virtude de Nietzsche ou a "nossa" virtude. Para além de ser a mais jovem ou a mais recente virtude, ela é também a última, de acordo com ele. Em uma nota não publicada de (Nachlass/FP 1 [144], KSA 12.44), encontramos um esboço para uma página de rosto. Sob o título sugerido "A última virtude", Nietzsche acrescenta como subtítulo: "Uma moralidade para moralistas". E na nota imediatamente subsequente explica: "essa última virtude, nossa virtude é chamada: probidade" (Nachlass/FP 1 [145] KSA 12.44). O que isso poderia significar? Por que ou em que sentido a probidade seria a "última virtude"?

Sabemos que Nietzsche reiteradamente censura toda a tradição da filosofia moral por não conseguir alcançar aquilo que ele denomina na seção 186: “o problema da própria moral”. Ao invés de investigarem a moralidade, eles tentaram encontrar uma fundamentação para a mesma, e: "o que os filósofos denominavam 'fundamentação da moral', exigindo-a de si, era apenas, vista à luz adequada, uma forma erudita da ingênua fé na moral dominante, um novo modo de expressá-la, e portanto um fato no interior de uma determinada moralidade, e até mesmo [...] o oposto de um exame, questionamento, análise, vivissecção dessa mesma fé." (JGB/BM 186, KSA 5.105) Encontramos mais uma vez esse mesmo criticismo imediatamente após a nossa seção 227, a saber, na seção 228: na medida em que os filósofos morais eram "enfadonhos advogados" da "virtude", faltando-lhes "a noção de que o refletir sobre a moral pode ser realizado de maneira perigosa, insidiosa, sedutora". É claro que Nietzsche quer ser diferente. Mas ele leva isso a cabo?

É significativo que ele expresse em seu texto a sua própria abordagem apenas entre aspas e na forma de uma pergunta retórica: "(Um moralista não é o contrário de um puritano? Ou seja, um pensador que vê a moral como questionável, interrogável, em suma, 
van Tongeren, $\mathrm{P}$.

como um problema? O moralizar não seria - imoral?)" (JGB/BM 228, KSA 5.163) A hesitação que pode ser expressa nesse "seria" será, na verdade, confirmada, precisamente nos termos de "nossa virtude": probidade. O criticismo nietzscheano da moralidade como "uma decidida e prolongada falsificação" (JGB/BM 291, KSA 5.235), o seu "sentido dessa mendacidade longamente incorporada" da interpretação moral (Nachlass/FP 5 [71], KSA 12.211), resulta em si mesmo de ser motivado por uma virtude moral, i.e., a probidade. Nietzsche está bastante ciente do fato de que a moralidade criticada está ela mesma mais uma vez presente no criticismo: "a moralidade em si mesma compele à negação da moralidade [Moral-Verneinung], por meio da probidade". Tenho a impressão de que esse insight se inicia em Aurora e n'A gaia ciência e se torna ainda mais forte até que ele domine o pensamento de Nietzsche em Para além de bem e mal e na Genealogia da moral. Já em 1884 ele se refere a isso: “Há algo na essência da moralidade que vai contra a probidade [...]. Como é então possível que haja uma 'probidade', que solapa a moralidade?" (Nachlass/FP 1884 25[101] 11.35)3. A última probidade, aquela que solaparia a moralidade, está aqui, em 1884, ainda colocada entre aspas; como se Nietzsche sugerisse (ou quisesse) que poderia haver um tipo diferente de probidade. Ele irá, contudo, descobrir pouco a pouco que isso é uma ilusão:

provavelmente também nós somos "bons demais" para o nosso ofício, provavelmente também nós somos ainda as vítimas, as presas, os doentes desse moralizado gosto atual, por mais que acreditemos desprezá-lo provavelmente até mesmo a nós ele infecta... (GM/GM, III, 20, KSA 5.387).

O sétimo capítulo de Para além de bem e mal é também sobre esse problema de ser moralmente motivado em sua tarefa imoral. O modo com que Nietzsche concebe essa condição problemática

3 Es ist also im Wesen der Moral Etwas, das wider die Redlichkeit geht [...]. Wie ist es nun möglich, daß es eine "Redlichkeit" gibt, welcher die Moral selber zersetzt.

232 | Cad. Nietzsche, Guarulhos/Porto Seguro, v.37, n.1, p. 219-241, 2016. 
Nossas virtudes: sobre o capítulo 7 de Para além de bem e mal

já é indicado na seção final do primeiro capítulo do livro, e é notoriamente sumarizado na fórmula de uma "autossuperação da moralidade", no parágrafo 32. Entretanto, essa "autossuperação da moralidade" não deve ser entendida como uma ressureição da moralidade de suas cinzas, mas antes como a realização de sua própria decadência. "Autossuperação" [Selbstüberwindung] deve ser, portanto, entendida como Selbstaufhebung; e esta não deve ser traduzida como "autossublimação" [selfsublimation], como Hollingdale o fez, mas antes como "autossupressão" [self-liquidation]. Com as palavras do prefácio de Aurora: "em nós se realiza, supondo que desejem uma fórmula - a autossupressão da moral" (M/A Prefácio 4, KSA 3.15).

Essa é a razão pela qual a probidade pode ser denominada "a última virtude": ela não sobrevive à sua própria atividade de solapamento. Essa virtude começa um perigoso caminho de pensamento, uma jornada arriscada; mas, após ter embarcado, seremos levados para além do horizonte de nosso ponto de partida. Como Nietzsche escreve na seção conclusiva do capítulo 1: "se o seu navio foi desviado até esses confins, muito bem: Cerrem os dentes! Olhos abertos! Mão firme no leme! - navegamos diretamente sobre a moral e além dela, sufocamos, esmagamos talvez nosso próprio resto de moralidade, ao ousar fazer a viagem até lá" (JGB/BM 23, KSA 5.38).

Eu disse que a virtude não irá sobreviver à sua própria atividade de solapamento. Talvez eu possa dizer: ela pode sobreviver, mas se assim ocorrer, ou naqueles em quem isso ocorre, ela será radicalmente modificada e se tornará profundamente problemática: “Ah, se vocês soubessem com que rapidez, com que rapidez - isso mudará" (JGB/ $B M$ 214, KSA 5.151). Se ela sobreviver, será do mesmo modo que a virtude na qual todas as virtudes desaparecem, será um dos modos nos quais a natureza paradoxal da "nossa" condição aparece, a condição que ele diagnostica como a fase final do niilismo, e que ele expressa na Genealogia da moral como se segue: “em nós essa vontade de verdade toma consciência de si mesma como problema" 
van Tongeren, $\mathrm{P}$.

(GM/GM, III, 27, KSA 5.408). A probidade é denominada "uma sarcástica luz de entardecer" (JGB/BM 227, KSA 5.162): ela se torna uma paródia da moralidade que ela supera. A última virtude é um ponto de inflexão, uma transição, como eu disse anteriormente; a seriedade se torna paródia. Entretanto, não devemos pensar tal paródia tão despreocupadamente. Ao fim do quinto livro d'A gaia ciência, Nietzsche descreve "um espírito que ingenuamente [...] brinca com tudo o que até aqui se chamou santo, bom, intocável, divino", um espírito

que com frequência parecerá inumano, por exemplo, ao colocar-se ao lado de toda a seriedade terrena até então, ao lado de toda a anterior solenidade em gesto, palavra, tom, olhar, moral e dever, como sua mais viva paródia involuntária - e com o qual, não obstante tudo, só então talvez alce $a$ grande seriedade, a verdadeira interrogação seja colocada, o destino da alma dê a volta, o ponteiro avance, a tragédia comece... ( $F W / G C$ 382, KSA 3.635).

Como sugeri anteriormente: a transição que ocorre na virtude da probidade resulta em um passo em direção à tragédia; esse "ultrapassamento" [going over] resulta em um "declínio" [going under] $(F W / G C 342$, KSA 3.571). A paródia é ao mesmo tempo uma tragédia: "Incipit tragoedia [...] incipit parodia" (cf. $F W / G C$ Prefácio 1, KSA 3.345).

\section{Tragédia e Paródia}

Gostaria de tomar esses dois conceitos, tragédia e paródia, como um ponto de partida e uma diretriz para a interpretação da segunda metade do capítulo 7. Esta metade, tal como dominada e concluída pela sua longa série de textos antifeministas, é talvez a parte mais difícil de interpretar no capítulo: por que afinal de contas concluiria Nietzsche um capítulo "Nossas virtudes" com uma série de aforismos sobre a "'mulher em si"” (JGB/BM 231, KSA 5.170)? 
Mas olhemos primeiramente as seções que precedem esses textos sobre a mulher.

A seção 227 conclui com a advertência de que a nossa probidade deveria ser impedida de nos tornar, ao invés de virtuosos, "enfadonhos" [bore] irritantes. A seção 228 se inicia e se encerra com uma referência ao tédio [boredom]: na sentença de abertura ele estabelece que "até agora todas as filosofias morais foram enfadonhas" e "que nada prejudicou mais 'a virtude' [...] do que o enfado de seus advogados"; e, ao fim, ele ridiculariza os utilitaristas, denominandoos "enfadonhos" [boring], mas então os elogia pela utilidade que está contida em seu enfado e ainda os encoraja a ser enfadonhos por meio de uma rima paródica. No início da segunda metade do capítulo, Nietzsche realiza aparentemente a transição da seriedade para o escárnio e a zombaria. Podemos provavelmente esperar que ele queira mostrar como a filosofia pode evitar o tédio. E, na verdade: o que quer que alguém possa pensar de seus textos sobre a mulher, eles não são certamente enfadonhos.

Ao fim do capítulo, tal impressão é confirmada: na seção 239 encontramos uma referência à tragédia como sendo oposta ao tédio, e Nietzsche sugere que o que ele fez foi um esforço de combater uma interpretação enfadonha da mulher:

temor e compaixão: com estes sentimentos o homem colocou-se até agora diante da mulher, sempre com um pé na tragédia, que dilacera ao encantar. - Como? E isso estaria acabando? O desencantamento da mulher está em marcha? Está surgindo o entediamento [Verlangweilung] da mulher? (JGB/ $B M$ 239, KSA 5.175).

Não apenas encontramos o tédio mais uma vez no fim da segunda parte do capítulo, mas também o seu oposto, a tragédia, pode ser reconhecida em seu início. A tragédia é mencionada brevemente na seção 229, mas ainda mais importante é o modo com que a tragédia parece estar implicitamente presente no conceito de natureza, tal 
van Tongeren, $\mathrm{P}$.

como este é usado na seção 230. Foi por causa de "sua natureza, que é 'mais natural' que a do homem”, que na seção 239 a influência da mulher foi comparada com a da tragédia. E é novamente em termos de "natureza" que Nietzsche sumariza a sua abordagem, tal como ele elabora nas três primeiras seções da segunda parte do capítulo. O que ele quer fazer é "retraduzir o homem de volta à natureza; triunfar sobre as muitas interpretações e conotações vaidosas e exaltadas, que até o momento foram rabiscadas e pintadas sobre o eterno texto homo natura" (JGB/BM 230, KSA 5.167). Esse "texto básico" é, de acordo com Nietzsche, "terrível" (uma palavra que Kaufman se esquece de traduzir) e, no intuito de extrair esse terrível texto básico, necessita-se de "intrépidos olhos de Édipo": uma referência óbvia à tragédia. A "probidade" é a "pompa verbal", com a qual a sua natureza é coberta. Ao parodiar a "honestidade", assim como "o amor pela verdade, o amor pela sabedoria, o sacrifício pelo conhecimento e o heroísmo do homem veraz", Nietzsche tenta liberar a natureza trágica.

Tal naturalização da probidade tem lugar nas seções 229 e 230. Em sua forma naturalizada, a probidade aparece como crueldade, a mesma crueldade que, de acordo com a seção 229, está na base da tragédia e de toda a cultura superior. E, assim que a probidade perde o seu encobrimento moral, ela pode voltar-se em direção a si mesma. Permitam-me tentar explicar com mais detalhes o que se passa aqui, e qual é a sua relação com a "mulher".

"Nossas virtudes" são as virtudes de nós mesmos, que somos pensadores, espíritos livres. A probidade terá uma posição central dentre essas virtudes, uma vez que ela é a aparência moral de um amor do pensador pela verdade. Essa veracidade foi tão central na primeira metade do livro quanto a probidade é na segunda. Mas ambas são submetidas a uma mudança dramática ao serem aplicadas a si mesmas. Precisamente do mesmo modo que a veracidade veio a solapar a si mesma no primeiro capítulo do livro, a probidade o 
faz no sétimo. $\mathrm{O}$ autoquestionamento da veracidade na primeira seção do primeiro capítulo tem como resultado a perda da origem e autoria do nosso questionar, e não mais sabemos "quem é Édipo, no caso? Quem é a Esfinge?" (JGB/BM 1, KSA 5.15). Do mesmo modo, também o autoquestionamento da probidade no capítulo 7 conduz a uma aporia. Na seção 230, Nietzsche explica como essa cruel tradução do homem de volta à natureza se torna a sua tarefa. Ao final daquele texto lemos:

por que a escolhemos, essa tarefa? Ou, perguntando de outro modo: "Por que conhecimento, afinal?" Todos nos perguntarão isso. E nós, premidos desse modo, nós, que já nos fizemos mil vezes a mesma pergunta, jamais encontraremos resposta melhor que... (JGB/BM 230, KSA 5.167).

O texto finaliza com uma elipse: não há nenhuma resposta para essa questão: nenhuma base sólida para este questionamento.

Mas isso não põe fim a tal questionamento, nem diminui o seu jogo, precisamente como a tragédia, "que", de acordo com a seção 239, "dilacera ao encantar." Contudo, a natureza desse questionar se alterou: depois de se libertar a si mesmo da camisa de força da virtude, ele se torna capaz de "dançar com nossas 'cadeias' e entre as nossas "espadas" (JGB/BM 226, KSA 5.162). O pensador que passou por esse processo "retorna como uma outra pessoa", como Nietzsche explica no prefácio de A gaia ciência:

com algumas interrogações mais, sobretudo com a vontade de ora em diante questionar mais, mais profundamente, severamente, duramente, maldosamente, silenciosamente do que até então se questionou. A confiança na vida se foi; a vida mesma tornou-se um problema. - Mas não se creia que isso torne alguém necessariamente sombrio. Mesmo o amor à vida é ainda possível - apenas se ama diferente. É o amor a uma mulher da qual se duvida... ( $F W / G C$, Prefácio, 3, KSA 3.349).

Que outro assunto iria se adaptar melhor para exemplificar 
van Tongeren, $\mathrm{P}$.

esse novo tipo de questionamento e pensamento que a "mulher"? E quando o tema é introduzido na seção 231 como a "mulher em si", é claro que a paródia será uma importante característica estilística desse novo modo de pensar.

O tema "mulher" já havia sido introduzido - além disso - no início do livro, que é apresentado como o "Prelúdio para uma filosofia do futuro", i.e.: um texto antecipatório no qual, como sabemos agora, um pensar cruel-honesto irá solapar a sua própria veracidade. A primeira linha do prefácio, que se tornou célebre, diz: "supondo que a verdade seja uma mulher". Na seção 220, Nietzsche havia relembrado o leitor mais uma vez de sua pressuposição e a vinculado à necessidade de se prevenir o tédio: "tanto a verdade é aqui obrigada a sufocar os bocejos quando tem de responder. Afinal ela é uma mulher: não se deve violentá-la" (JGB/BM 220, KSA 5.154).

Isso também explica o tom polêmico desses textos sobre a mulher: tais textos irão antes escandalizar do que causar tédio. A filosofia é amor pela sabedoria. Nietzsche faz Zaratustra dizer: "despreocupados, escarninhos, violentos - assim nos quer a sabedoria: ela é mulher e ama somente quem é guerreiro" ( $Z a / Z A$, I, Do ler e escrever, KSA 4.48). Um guerreiro é sempre parcial, ele não é um "homem objetivo", mas um tal homem representa "nada para as mulheres" (JGB/BM 207, KSA 5.134 ). Um guerreiro luta e vence. Como ele poderia expressar as suas verdades de outro modo que não polemicamente?

O pensador deve impedir que a verdade comece a bocejar, e, por essa razão, ele não deve ser "desinteressado" (JGB/BM 220, KSA 5.154), mas pessoalmente envolvido. Por isso, o novo modo de pensar é introduzido na seção 231, ao sublinhar o seu caráter pessoal: "em todo problema cardinal fala um imutável 'sou eu'; sobre o homem e a mulher, por exemplo, um pensador não pode aprender diversamente, mas somente aprender até o fim - descobrir inteiramente o que nele está 'firmado' a esse respeito" (JGB/BM 231, 
KSA 5.170). Isso relaciona a série de textos sobre a mulher com o tema da virtude em geral, assim como com o destino da virtude da probidade, tal como acabamos de compreendê-la agora.

Virtudes são, como sabemos, não ações, mas disposições. Elas não denotam deveres universalizáveis, mas os traços de caráter melhores possíveis de uma pessoa em particular. As virtudes são pessoais e individuais, também de acordo com Nietzsche: "'sua virtude é a saúde de sua alma'. Pois não existe uma saúde em si” (FW/GC 120). Nietzsche sublinha o caráter pessoal de suas "verdades acerca da "mulher em si", ao supor "que desde já se saiba que são apenas verdades minhas." (JGB/BM 231).

Essa natureza pessoal de suas "verdades" se refere ao mesmo tempo, entretanto, à natureza paradoxal da probidade como "nossa virtude". Nietzsche não está se referindo, penso eu, apenas ao compromisso pessoal exigido por um verdadeiro pensador, ao falar na seção 231 deste "sou eu" que fala em todo "problema cardinal". Algumas linhas adiante ele descreve este "eu" como "o problema que nós somos" [das Problem das wir sind]. Este problema que nós somos se torna visível quando nós descobrimos que as nossas “convicções', opiniões que justamente a nós nos inspiram uma forte fé", apenas se referem à "grande estupidez que somos, para o nosso fatum espiritual, o que não aprende "lá embaixo" (JGB/BM 231, KSA 5.170). Somos relembrados da conclusão da Genealogia da moral:

que em nós essa vontade de verdade toma consciência de si mesma como problema [...] Nesta gradual consciência de si da vontade de verdade - disso não há dúvida - perecerá doravante a moral: esse grande espetáculo em cem atos reservados para os próximos dois séculos da Europa, o mais terrível, mais discutível e talvez mais auspicioso entre todos os espetáculos... (GM/ GM 27, KSA 5.408).

Nietzsche obviamente se refere àquilo que ele descreve nesse período como "niilismo". No famoso texto de Lenzer Heide sobre o 
van Tongeren, $\mathrm{P}$.

niilismo, Nietzsche explica o niilismo como o processo de dissolução que resulta do "antagonismo - não estimar o que sabemos e não ser mais permitido estimar as mentiras que deveríamos contar a nós mesmos" (Nachlass/FP 5 [71] § 2, KSA 12.211). Isso é precisamente o que encontramos no que diz respeito à "nossa virtude": probidade. Permanecemos comprometidos com a virtude que solapa a sua própria virtuosidade.

Se nós, leitores contemporâneos, achamos difícil reconhecer uma virtude, para não dizer a virtude da probidade, nesses textos polêmicos e aparentemente antifeministas, isso pode significar que nós nos equivocamos "no problema fundamental "homem e mulher" (JGB/BM 238, KSA 5.175). Isso poderia ainda significar - para concluir na esteira do sétimo capítulo de Para além de bem e mal que "também nós usamos [a] trança [de nossos avós]" (JGB/BM 214, KSA 5.151), que a nossa virtuosidade se tornou na verdade "nosso limite, nossa estupidez" (JGB/BM 227, KSA 5.162), a estupidez na qual nós nos escondemos e com a qual nos protegemos da ameaça do niilismo.

\footnotetext{
Abstract: What is Nietzsche's message in the seventh chapter of Beyond Good and Evil: 'our virtues'? First an analysis of the structure of the chapter (which itself seems to be the central chapter of the second half of the whole book) is presented. From that analysis sections 214 and 227 appear to be of special importance. An analysis of mainly these two sections suggests that in this chapter the reader is being introduced into a typical Nietzschean condition: the critical questioning of morality is being made selfreferential: the questioner makes his own questioning questionable. What Nietzsche did in section 1 of the first chapter with regard to philosophy and the will to truth (the traditional will to truth one as well as 'our' own), is now, in the second half of the book repeated with regard to 'honesty' or 'probity' [Redlichkeit] and so applied to morality (again: traditional, as well 'our' moral virtue). What in the beginning looks like being a presentation of the free spirit's moral virtue, turns out to be a 'self-liquidation' of morality. The interpretation is elaborated and confirmed by the clarifying
}

240| Cad. Nietzsche, Guarulhos/Porto Seguro, v.37, n.1, p. 219-241, 2016. 
light it sheds on the allegedly anti-feminist texts in the last part of the chapter.

Keywords: virtue - morality - honesty - probity

\section{Referências bibliográficas}

NIETZSCHE, Friedrich. Sämtliche Werke. Kritische Studienausgabe, Berlim: Walter de Gruyter \& Co., 1967/1978. 15 vols. (Organizada por Giorgio Colli e Mazzino Montinari).

. Humano, demasiado humano. Trad. de Paulo César de Souza. São Paulo: Cia. das Letras, 2000.

.Assim falou Zaratustra. Trad. de Paulo César de Souza. São Paulo: Cia. das Letras, 2009.

. Aurora. Trad. de Paulo César de Souza. São Paulo: Cia. das Letras, 2004.

- A gaia Ciência. Trad. de Paulo César de Souza. São Paulo: Cia. das Letras, 2001.

. Além do bem e do mal. Trad. de Paulo César de Souza. São Paulo: Cia. das Letras, 1999.

- Genealogia da moral. Trad. de Paulo César de Souza. São Paulo: Cia. das Letras, 1998.

Artigo recebido para publicação em 11/10/2015.

Artigo aceito para publicação em 30/11/2015. 